\title{
Vaping Related Lung Injury: A New Epidemic
}

\author{
Ravinder Kaler* and Girish B Nair \\ Department of Medicine, Beaumont Hospital, Royal Oak, USA
}

Submission: November 04, 2019; Published: December 13, 2019

*Corresponding author: Ravinder Kaler, Department of Medicine, Beaumont Hospital, Royal Oak, USA

\section{Introduction}

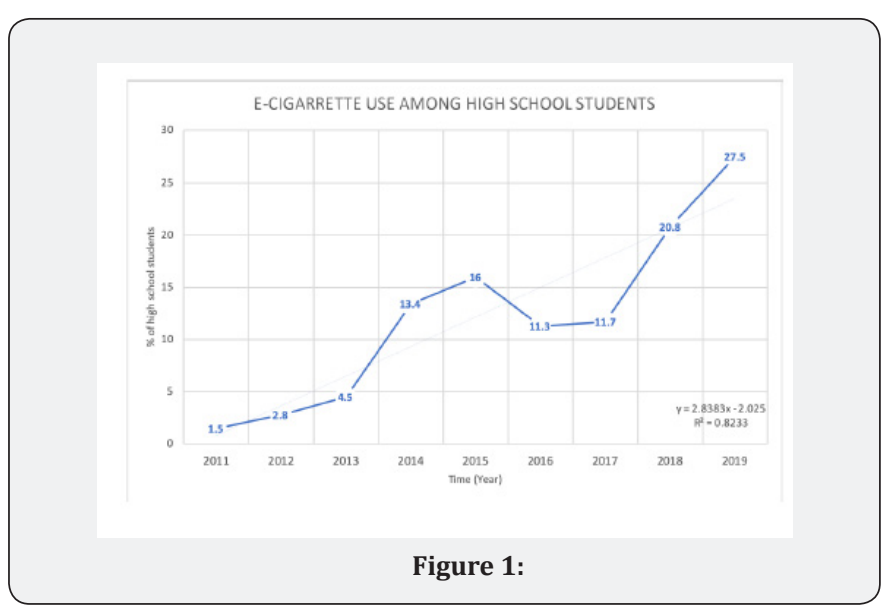

Over the last several months, the Center for Disease Control and Prevention (CDC) has reported 34 confirmed deaths and over 1600 cases of lung injuries related to e-cigarettes and vaping [1]. E-cigarettes were initially introduced as a cleaner alternative to help cigarette smokers quit smoking and gradually decrease nicotine levels. However, its use has dramatically increased due to the number of different products and flavors available for users to vape. These products have become increasingly popular amongst teenagers and young adults. High school e-cigarette use has increased from $1.5 \%$ in 2011 to $27.5 \%$ in 2019 (Figure1) [2,3]. Currently there are 3.5 million high school students using e-cigarette [4]. E-cigarettes are battery operated devices that heat an oil solution and deliver vaporized products such as tobacco, tetrahydrocannabinol (THC), cannabidiol (CBD), flavorings and other potentially harmful substances to the user. Though the mechanism of the use of e-cigarettes leading to lung injury is not yet certain, it is believed that they are caused by a severe inflammatory reaction. The liquid solution is heated during aerosolization to become vapor for the user to inhale. However, as the oil cools down, there is a possibility of some of the residual droplets could be inhaled as well. When this oil gets into the lungs, the innate lung immunity with alveolar macrophages tries to limit the injury. The resulting inflammatory reaction causes acute and sub-acute lung injury. Most patients present with bilateral basilarpredominant ground glass opacities, with sub pleural sparing on imaging $[5,6]$. Histopathological findings most commonly show patterns of acute lung injury with neutrophil predominance, pneumocyte vacuolization, and foamy macrophages [7]. These patterns also include acute fibrinous pneumonitis, diffuse alveolar damage, and bronchiolocentric organizing pneumonia accompanied by bronchiolitis [8]. Patients usually present with cough and dyspnea. Recent reported cases describe patients presenting with acute respiratory failure (Figure 2). Treatment is usually supportive. Vaping itself is not considered a drug; it is what one vapes that makes it harmful. Health officials have not yet linked any specific substance or single product being the cause of the lung injury, as it is extremely difficult to regulate the ingredients of the vaping liquids from various manufacturers [9]. This said, it is highly understood that eighty-six percent of the vaping related lung injury cases reported were linked to cannabis related products, THC being the most concerning [10]. Most of the THC products were obtained illegally off the street, the dark web, from friends or family, and other unregulated sources. The legalization of marijuana has made THC containing products so readily available to the public. Unfortunately, if these products were banned, consumers would still be able to find a way to purchase them through illegitimate sources. The best approach to this epidemic is through harm reduction, increasing public awareness, and educating users about the unknown hazardous chemicals in these unregulated illicit products. Given vaping is most popular amongst teenagers, they should be the targeted audience we focus on. Addressing this issue at a young age and warning students about the harmful effects of vaping can help them make better choices. Educating the public on acquiring these products from licensed dispensaries and regulated sources will decrease the likelihood of contaminated and laced foreign toxins being vaped. This will also help researchers and doctors identify the compounds causing this illness. Finally, by educating the users on recognizing the signs and symptoms associated with vaping related lung illnesses, individuals will be able to increase their chances of survival by seeking treatment earlier. We also need 
more research focus on vaping related lung injury and methods to develop better devices and filters that are well regulated.

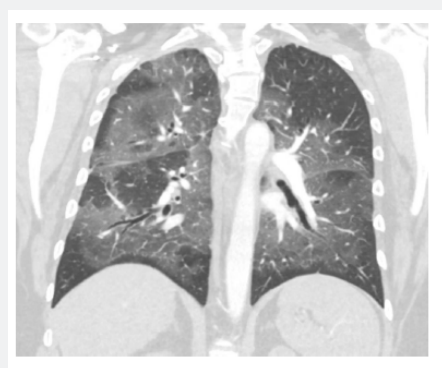

Figure 2: $48 \mathrm{yr}$. female with bipolar disease admitted with acute respiratory failure secondary to vaping related lung injury.

\section{References}

1. Outbreak of Lung Injury Associated with the Use of E-Cigarette, or Vaping, Products (2019).
2. Youth Tobacco Use: Results from the National Youth Tobacco Survey (2019).

3. National Youth Tobacco Survey (NYTS) (2019).

4. Youth Tobacco Use: Results from the National Youth Tobacco Survey (2019).

5. Imaging of Vaping-Associated Lung Disease (2019).

6. Imaging of Vaping-Associated Lung Disease (2019). Pathology of Vaping-Associated Lung Injury (2019).

7. Pathology of Vaping-Associated Lung Injury (2019).

8. Outbreak of Lung Injury Associated with the Use of E-Cigarette, or Vaping, Products (2019).

9. Outbreak of Lung Injury Associated with the Use of E-Cigarette, or Vaping, Products (2019).

\section{Your next submission with Juniper Publishers} will reach you the below assets

- Quality Editorial service

- Swift Peer Review

- Reprints availability

- E-prints Service

- Manuscript Podcast for convenient understanding

- Global attainment for your research

- Manuscript accessibility in different formats

( Pdf, E-pub, Full Text, Audio)

- Unceasing customer service

Track the below URL for one-step submission https://juniperpublishers.com/online-submission.php 